\title{
Contribuições teóricas sobre um repensar da percepção de velhice: aliada à discussão de classe e hegemonia
}

\section{Rethinking the perception of old age combined with the discussion of class and hegemony}

DOI: $10.46814 / \mathrm{lajdv} 2 \mathrm{n} 4-002$

Recebimento dos originais: 10/04/2020

Aceitação para publicação: 10/04/2020

\author{
Juliana de A. F Doronin \\ Doutoranda em Ciências Sociais pela Pontifícia Universidade Católica de São Paulo - PUC-SP \\ Instituição: Pontifícia Universidade Católica de São Paulo - PUC-SP \\ Endereço: Rua Ministro Godoy, 969, 4 . andar - Sala 4E-20, CEP: 05015-901 Perdizes, São \\ Paulo/SP, Brasil. \\ E-mail: julianadoronin@ hotmail.com \\ Giovanna de Aquino Fonseca Araújo \\ Pós-doutora em História pela Universidade Federal de Campina Grande - UFCG. \\ Instituição: Prefeitura Municipal de Campina Grande/ SEDUC- Coordenação de Educação \\ Patrimonial \\ Endereço: CTE- Centro de Tecnologia Educacional. Av. Santa Clara, Centro. 58.400-170, Campina \\ Grande, Paraíba, Brasil \\ E-mail: coordenacaoedupatrimonialseduc@gmail.com
}

\section{RESUMO}

O texto parte de reflexão/discussão acerca das subjetividades da construção do (s) sujeito (s) velho (s) enquanto categoria de classe e questão social, relacionando com o campo da política no sentido de pensar se alguns grupos de idosos de experiências no âmbito da educação vinculados a Instituições públicas podem ser considerados, aparelhos ideológicos do Estado da hegemonia discutida por Gramsci, através de práticas, rituais e comportamentos, instituídos dentro dos próprios grupos, enquanto formas de viver. Foi realizada pesquisa bibliográfica no qual se utilizou como principais referências: GRAMSCI (1978) MILIBAND (1976) e POULANTZAS (1975).

Palavras-chave: velhice, classe social, questão social, aparelho ideológico, hegemonia

\begin{abstract}
The text starts from a reflection / discussion about the subjectivities of the construction of the old subject (s) as a category of class and social issue, relating to the field of politics in the sense of thinking if some groups of elderly people experiences public institutions can be considered, ideological apparatuses of the state of hegemony discussed by Gramsci, through practices, rituals and behaviors, instituted within the groups themselves, as forms of living. A bibliographic research was carried out in which GRAMSCI (1978) MILIBAND (1976) and POULANTZAS (1975) were used as main references.
\end{abstract}

Keywords: old age, social class, social issue, ideological apparatus, hegemony 


\section{INTRODUÇÃO}

Muitos estudos contemporâneos em todo mundo, inclusive no Brasil, demonstram que os números de pessoas acima de 60 anos têm crescido substancialmente em relação a outras faixas etárias. Estima-se (World Health Organization, 2005) que em 2025 haverá 1,2 bilhões de pessoas com mais de 60 anos no mundo, e o Brasil será o sexto país do mundo em número de idosos.

Pesquisas e investimentos principalmente na área da saúde e na indústria farmacêutica e de cosméticos estão em evidência em todo o mundo na busca em "retardar" o envelhecimento que é um processo natural, com investimentos em fórmulas "mágicas e mirabolantes" defendidas em pelo estereótipo do envelhecimento saudável, vinculando o conceito de velhice ao estigma do "fim de linha”, pautado pela máquina do capital que privilegia a produtividade, lucratividade e rotatividade.

O conceito de velhice ou envelhecimento no mundo contemporâneo e especificamente no capitalismo do Brasil está associado à ideia de classe social e a questão social definido enquanto “conjunto de desigualdades sociais", formada pelas relações sociais estabelecida no capitalismo e, portanto historicamente ligada à questão da exploração da força de trabalho, à mobilização da classe operária na luta pelo apoderamento da riqueza social (FERNANDES e DORONIN, 2017).Fazemos aqui uma associação à velhice, no qual os indivíduos passam a serem considerados improdutivos, uma vez que se vincula o tempo de trabalho (força de trabalho) ao tempo de vida (útil), baseado no modo de produção capitalista de exploração.

Ao trabalhador velho lhe é imputado um estigma o qual é reproduzido pelo sistema capitalista. Com a aposentadoria, o idoso já não mais vende a sua força de trabalho e ainda que retorne ao mercado, não contribui com processo de acumulação na mesma intensidade de antes, dessa forma, o velho torna-se improdutivo para o capital (MUNIZ; BARROS, 2014, p.110).

Nesse sentido, ocorre a associação de elementos negativos ligados à velhice que ultrapassam os tempos, onde concepções de velhice passam a serem resultados de uma construção social e temporal feita no seio de uma sociedade com valores e princípios próprios, atravessados por questões multifacetadas, multidirecionadas e contraditórias. Florescer no século XXI, portanto, é potencializado pela ideia de longevidade, se negando aos velhos o seu valor e sua importância social, vivendo o consumo no qual apenas o novo pode ser valorizado, caso contrário, não existe produção e acumulação de capital (Op cit. FERNANDES e DORONIN, 2017).

Além disso, há outra questão que nos parece ainda mais relevante. Trata-se da concepção de velhice categorizada em classe social, ou seja; de um lado a "velhice associada à questão social", limitada e perversa, "além de velho o sujeito ainda eh pobre dando despesa para o Estado"1.

\footnotetext{
${ }^{1}$ Afirmação, utilizada como forma de "jargão", pela elite de direita, quando se referem ao BPC -O Benefício de Prestação Continuada da Lei Orgânica da Assistência Social- LOAS (BPC), que garante o direito de um salário mínimo mensal ao
} 
Por outro lado, existe a "velhice saudável", representada pelo idoso cliente de agências de viagens e laboratórios de cosméticos que são "bem aceitos" por serem alvos de consumo na busca da "longevidade mercadológica".

Porém, todos são pertencentes à mesma faixa etária e sujeitos dos mesmos direitos sociais, previstos pela legislação que desconsidera as singularidades e realidades dos sujeitos.

Art. $1^{\circ}$ A política nacional do idoso tem por objetivo assegurar os direitos sociais do idoso, criando condições para promover sua autonomia, integração e participação efetiva na sociedade. Art. $2^{\circ}$ Considera-se idoso, para os efeitos desta lei, a pessoa maior de sessenta anos de idade.

Esse processo que é considerado "democrático" no Brasil, considerando as políticas publica dito como "universais", nos faz refletir que há diferentes concepções de democracia em jogo quando se trata de lutas sociais, como afirma SAES (2017), com defesa de diferentes concepções que podem se repartir entre diferentes classes sociais ou mesmo, numa mesma classe. Ou seja; tudo depende dos interesses postos.

Além disso, as determinações estruturais da sociedade não se restringem exclusivamente ao nível das relações econômicas, mas abrangem o nível das relações ideológicas e políticas, incluindo o pertencimento de classe dos diversos agrupamentos sociais POULANTZAS (1975).

Significando, portanto, que a categoria velhice está associada há diversas relações econômicas, políticas e ideológicas-, definidas e vivenciadas por sujeitos de uma mesma classe e / ou de classes diferentes e as políticas públicas, independente de como são elaboradas, implantadas e implementadas, são constatações que fazem parte de diversos interesses de classes, inclusive dentro de uma mesma classe ou categoria, aqui destacada como velhice.

\section{DESENVOLVIMENTO}

$\mathrm{Na}$ pesquisa de doutorado em andamento, realizada pela primeira autora deste texto ${ }^{2}$, vinculada ao Programa de Pós Graduação em Ciências Sociais (PUC-SP),intitulada "A arte de viver: experiências universitárias com a educação aberta às velhices”, se pretende analisar experiências com educação da Universidade aberta à Terceira Idade: projeto "UNATI”, já consolidado desde 2009 da UEM (Universidade Estadual de Maringá) de cunho permanente e o projeto extensionista "Viver Melhor", mais recente (2015-2018) da UNESPAR (Universidade Estadual do Paraná-Campus

\footnotetext{
idoso acima de 65 anos ou à pessoa com deficiência de qualquer idade com impedimentos de natureza física, mental, intelectual ou sensorial de longo prazo (aquele que produza efeitos pelo prazo mínimo de 2 (dois) anos), que o impossibilite de participar de forma plena e efetiva na sociedade, em igualdade de condições com as demais pessoas. Para se ter direito ao benefício, é necessário que a renda por pessoa do grupo familiar do idoso, seja menor que 1/4 do saláriomínimo vigente. Disponível em: http://mds.gov.br/assuntos/assistencia-social/beneficios-assistenciais/bpc. Acessado em 3 /11/2017).

${ }^{2}$ Aprovada em exame de qualificação em 04 de junho de 2020, sob orientação da Profa. Dra. Silvana Tótora (PUC-SP).
} 
Paranavaí), onde serão entrevistados idosos e familiares participantes das experiências dos grupos citados, e outras experiências com foco na cidadania, com o objetivo principal de perceber o impacto que essas experiências trazem na vida dos idosos e de que maneira elas são evidenciadas na prática, no caminho da criticidade ou apenas reproduzindo o que traz às legislações sobre velhice, integrando o idoso na perspectiva de ser único independente da sua realidade histórico-cultural.

Para isso, foi-se necessário, investigarmos na pesquisa de doutorado da primeira autora deste texto, após ser repensado no trabalho final da ATP e rediscutido com segunda autora para elaboração deste artigo, no tocante aos participantes das experiências universitárias (Unati/UEM e Viver Melhor/UNESPAR), as construções desse sujeito acerca da velhice e as contribuições dessas experiências percebidas no seu (s) cotidiano (s) relacionado aos aspectos da cidadania. E são, sobre essas construções, - subjetivas desse sujeito-, acerca da velhice que trazemos como principal conteúdo de nossa discussão, ampliando para o campo da política no sentido de pensarmos se esses grupos podem ser considerados como aparelhos ideológicos do Estado (já que estão vinculados a equipamentos educacionais públicos), da hegemonia discutida por Gramsci, que apresenta uma noção de hegemonia mais elaborada e adequada para pensar as relações sociais, sem cair no materialismo vulgar e no idealismo encontrado na tradição.

A noção de hegemonia ${ }^{3}$,propõe uma nova relação entre estrutura e superestrutura e tenta se distanciar da determinação da primeira sobre a segunda, mostrando a centralidade das superestruturas na análise das sociedades avançadas. Ultrapassando, portanto, um conjunto de ideias, através de práticas, rituais e comportamentos, instituídos dentro dos próprios grupos, enquanto forma de viver.

Questões são postas para refletirmos: de que maneira esses sujeitos pensam a velhice?; de que maneira eles reconhecem a velhice nestes espaços? Pensam e sentem a velhice a partir da mesma concepção por se sentirem seres coletivos- no sentido de grupo- ou percebem a velhice de maneira diferente associada às suas necessidades pautadas nas suas construções históricas de vida, singulares e principalmente da realidade social vivida por esses sujeitos?

Sabemos que dentro de uma mesma classe social há presença de estratificações e também de correlações de forças ou outros sistemas de conceitos nos quais à palavra classe, "funciona dentro de corpos com diferentes significados". De maneira que; se pensarmos esses sujeitos coletivos pesquisados, mesmo que pertencentes a um mesmo grupo (como é o caso dessas experiências), a velhice pode ter diferentes interpretações, dentro inclusive de uma mesma classe social como mencionamos, e, por conseguinte o foco na cidadania e/ou democracia também.

${ }^{3}$ Disponível em: http://www.scielo.br/pdf/ln/n80/04.pdf, acessado em novembro de 2017. 
Nessas experiências com idosos (a), se discute e se vivência de diferentes formas e abordagens temas contemporâneos ligados à educação, saúde, filosofia, política, tecnologia e outros relacionando com a velhice e/ou envelhecimento.

Porém a direção e a condução que os participantes do grupo (idosos e representantes institucionais) dão aos trabalhos podem ser diferentes, pois reproduzem os interesses dos membros dirigente e/ou não dirigentes- e, por conseguinte, a forma de pensar e sentir a velhice podem estar associados a esses interesses que são ideológicos, políticos e estruturais.

Nesse sentido, podemos pensar esses grupos, como parte de aparelhos ideológicos tratados por Gramsci, uma vez que; são formados pela sociedade civil (classes sociais e estado) que vivenciam através de conjuntos de práticas, rituais e comportamentos em aparelhos físicos - nas reuniões-, formas de viver.

Portanto, esses grupos, passam a terem um papel político importante, no sentido que podem ser pensados como espaços de esfera de produção da hegemonia, através dos sujeitos com a função de intelectuais orgânicos e, além disso, podem representar a concepção "instrumental" do Estado( MILBAND:1972) uma vez que; estão vinculados a organizações hierarquizadas-Instituições educacionais públicas(UNESPAR/PR e UEM/PR), ou seja; a hegemonia sobre os dominados colocados por Gramsci, explicitado por um conjunto da sociedade que nem sabem que são dominados.

\section{CONSIDERAÇÕES FINAIS}

A questão posta na pesquisa de tese e retomada neste texto é intrigante: De que maneira esses sujeitos pensam e sentem a velhice- suas construções subjetivas- e quais as contribuições dessas experiências percebidas no seu (s) cotidiano (s) relacionado aos aspectos da cidadania- no caminho da criticidade ou apenas reproduzindo o que traz às legislações sobre velhice, integrando o idoso na perspectiva de ser único independente da sua realidade histórico-cultural-?

Diante das discussões /reflexões apontadas, percebemos que a concepção de velhice pode ser sentida, percebida, reconhecida e tratada de diferentes formas e sentidos enquanto categoria de classe, independente do grupo que o sujeito esteja vinculado, pois a idéia de classe social não se limita a teoria da estratificação social e das condições exclusivamente objetivas, elas são também subjetivas e, portanto além de econômica, são ideologicas e politicas.

Dessa forma, experiências grupais que dialoguem sobre temáticas contemporanêas com foco na cidadania e /ou democracia, que se vinculam hierarquicamente a burocracia do Estado, motivadas pela busca do bem comum na prática, podem ser pensadas como aparelhos ideologicos de 
experiências que vivenciam e reproduzem em seus espaços à esfera da produção hegemônica do Estado.

Em síntese, para discutir aspectos de cidadania e /ou democracia com proposições inclusive de implantação e implementação de política pública para determinado segmento da sociedade no caso o idoso, é necessário se perceber que diferentes concepções perpassam a definição desse sujeito, pertencente a uma classe com interesses objetivos e subjetivos que o definem enquanto sujeito propositor e articulador. Além disso, esses participantes tidos como intelectuais orgânicos, quando se vinculam a burocracia de Estado podem ser "usados" como "funcionários da hegemonia".

É preciso ficar atento a essas questões, para defendermos esses espaços como luta hegemônica, assim como na educação, politica, igreja para transformação. Ou seja; a defesa desses espaços de experiência grupal enquanto uma força contra hegemônica, contra a hegemonia burguesa do Estado, vinculada a essas experiências, pela burocracia.

Cabe mencionar ainda que; neste artigo foram feitas, breves reflexões e discussões acerca do assunto, com intuito de resgatar a relação feita com os conteúdos da ATP citado no resumo deste texto com elementos de projeto de pesquisa, e aqui rediscutido sobre esses aspectos, numa tentativa de provocação e reflexões à cerca do assunto, mantendo a originalidade das ideias centrais do primeiro trabalho.

Este artigo parte da contribuição na íntegra do texto intitulado: "Repensando a percepção da Velhice aliada à discussão de Classe e Hegemonia", foi publicado como capítulo $14^{\circ}$ do E-book "Ciências Sociais Aplicadas: Entendendo as Necessidades da Sociedade"- ISBN: 978-85-7247-424-5 e DOI 10.22533/at.ed.24519250614, disponível em:https://www.atenaeditora.com.br/wpcontent/uploads/2019/07/e-book-Ciencias-Sociais-Aplicadas-Entendendo-as-Necessidades-daSociedade-2-2.pdf, pela Atena Editora ( Ponta Grossa - PR) . O artigo partiu da discussão do texto intitulado: "A percepção da velhice aliada à discussão de classe e hegemonia "Fundamentado no trabalho final na ATP cursada pela primeira autora na PUC-SP que após aprovação, foi rediscutido com segunda autora e reconstruído por ambas, mantendo a originalidade de ideias e título, publicado nos Anais do $6^{\circ}$ Encontro Internacional de Política Social $13^{\circ}$ Encontro Nacional de Política Social (ENPS/ Vitória-ES). 


\section{REFERÊECIAS}

ALVES, Ana R. C. O conceito de hegemonia: de Gramsci a Laclau e Mouffe Lua Nova, São Paulo, 80: 71-96, 2010. Disponível em: http://www.scielo.br/pdf/ln/n80/04.pdf. Acesso 13 de Novembro de 2017.

ARCURI, Irene Gaeta. (Org.). Envelhecimento e velhice: um guia para a vida. São Paulo: Vetor, 2006.

AMMANN, Safira B. Participação social. São Paulo: Cortez e Morais, 1979.

AVRITZER, Leonardo. “Teoria democrática, esfera pública e participação local”. Sociologias, Porto Alegre, ano 1, n. 2, jul/dez 1999.

BRASIL. Constituição (1998). Constituição da República Federativa do Brasil. Brasília, DF: Senado Federal, 1988.

Política Nacional do Idoso. Lei no 8.842, de 4 de janeiro de 1994. . Estatuto do Idoso. Lei n ${ }^{\circ} 10.741$, de 1 de outubro de 2003.

dezembro DE 1993.

Lei $n^{\circ}$ 8742. Lei Orgânica da Assistência Social (LOAS). Brasília: DF, 7 DE

CACHIONI, M. \& Neri, A. L. "Educação e velhice bem-sucedida no contexto das universidades da terceira idade". In A. L. Neri \& M. S. Yassuda (Orgs). Velhice bem-sucedida. Campinas: Papirus, 2004.

CACHIONI, M. "Universidade da Terceira Idade". In A. L. Neri (Org.), Palavras-chave em Gerontologia. Campinas: Alínea, 2005.

. "Educação permanente: perspectiva para o trabalho educacional com o adulto maduro e o idoso". In: EV Freitas. Tratado de Geriatria e Gerontologia. 2ed. Rio de Janeiro: Guanabara Koogan, 2006.

CASARA, Mirian B., CORTELLETTI, Ivonne A., BOTH, Agostinho. Educação e envelhecimento humano. Rio Grande do Sul: EDUCS, 2006.

CORTELLETTI, IA, Casara MB, Both A. (organiz.). Educação e envelhecimento humano. Caxias do Sul: Educs, 2006.

CURY, Mauro J. OLIVEIRA, Rita de Cassia da S., COENGA, Rosemar E. As interfaces da velhice na pós-modernidade avanços e desafios na conquista da qualidade de vida. Cascavel: EDUNIOESTE, 2013.

FERNANDES, Thais O; Doronin, Juliana de A. F. A velhice como questão social, frente ao capitalismo. Revista Portal de Divulgação, São Paulo, SP. N.54, Ano VIII. Out./nov./dez. 2017. Disponível em: http://www.portaldoenvelhecimento.com/revistanova/index.php/revistaportal/article/view/684/754. Acesso em 12 de novembro de 2017.

GRAMSCI. 1978. Maquiavel, a política e o Estado moderno. Rio de Janeiro: Civilização Brasileira. 
GOHN, M. G. Movimentos Sociais no Início do Século XXI: antigos e novos atores sociais. Petrópolis, RJ: Vozes, 2003.

IBGE. Instituto Brasileiro de Geografia e Estatística. IBGE: população brasileira envelhece em ritmo acelerado. $\quad$ IBGE, 2008.2 Disponível em <http://www.ibge.gov.br/home/presidencia/noticias/noticia_visualiza.php?id_notic ia=1272>Acesso em 15 novembro de 2017.

IBGE. Instituto Brasileiro de Geografia e Estatística. IBGE: - Tábua Completa de Mortalidade para o Brasil de 2012. IBGE, 2012. Disponível em <http://www.ibge.gov.br/home/estatistica/populacao/tabuadevida/2012/de.sht m> Acesso em 15 novembro de 2017.

IBGE. Instituto Brasileiro de Geografia e Estatística. Cidades. Município de Paranavaí - PR. Disponível em: <http://www.cidades.ibge.gov.br/xtras/perfil. php?lang=\&codmun=411840\&searc $\mathrm{h}=$ parana\%7Cparanavai> Acesso em: Acesso em 15 novembro de 2017.

KACHAR, Vitória. Longevidade, um novo desafio para a educação. 1o ed. São Paulo: Ed. Cortez, 2001.

LIBÂNEO, José Carlos. Democratização da Escola Pública - A Pedagogia Crítico-Social dos Conteúdos. $18^{\circ}$ ed. São Paulo: Edições Loyola, 2002.

MARSHALL, T. H. Cidadania, Classe Social e Status. Rio de Janeiro: Zahar Editores, 1967.

MAY, T. Pesquisa social: questões, métodos e processos. Porto Alegre: ArtMed, 2004.

MEDEIROS, Almira Lins de. Governabilidade, Educação e Normatização: As práticas de subjetivação da Universidade Aberta à Maturidade. Tese apresentada ao Programa de Pós-Graduação em Ciências Sociais da UFCG, 2013.

MEIHY, J. C. S. B. Manual de História Oral. 4ª edição. São Paulo: Edições Loyola. 2002.

MEIHY, J. C. S. B. (org.). “(Re) introduzindo História Oral no Brasil”. Xamã. São Paulo.

MINAYO, Maria Cecília de S. O desafio do conhecimento: pesquisa qualitativa em saúde. 5 ed. São Paulo: Hucitec, 2000.

Garrido, J. del A. I. “As fontes orais na pesquisa histórica: uma contribuição ao debate”. Revista Brasileira de História, 25/6, 1996.

MILIBAND (Ralph). O Estado na sociedade capitalista. Rio de Janeiro. Zahar. 1972.

MUNIZ, T.S.; BARROS, A. O trabalhador Idoso no Mercado de Trabalho do Capitalismo Contemporâneo. Cadernos de graduação. Maceió v.2, n.1, p.103- 116 maios 2014. Disponível em: https://periodicos. set.edu.br/index.php/fitshumanas/article/download /1079/793. Acesso em 12 de novembro de 2017.

PROJETO DE PESQUISA.A arte de viver: experiências universitárias com a educação aberta às velhices. São Paulo: PUC, 2016. 
SAES, Décio Azevedo Marques de. Cidadania e capitalismo: uma crítica à concepção liberal de cidadania.

Disponível

em:

https://www.ifch.unicamp.br/criticamarxista/arquivos_biblioteca/artigo9316saes.pdf. Acesso: 12 de novembro de 2017.

POULANTZAS, Nicos. 1975. As Classes Sociais no Capitalismo de hoje. Zahar: Rio de Janeiro: RJ

SANTOS, Boaventura. Democratizar a democracia: os caminhos da democracia participativa. Rio de Janeiro: Civilização Brasileira, 2002.

SAVIANI, Demerval. Pedagogia Histórico-Crítica: primeiras aproximações. 7 ed. Campinas, SP: Autores Associados, 2000.

THOMPSON, P. A voz do passado: história oral. $2^{\text {a }}$ edição. Rio de Janeiro: Paz e Terra. 1998.

TAAM, Regina. “A educação do idoso: Uma questão contemporânea”. In: ALTOÉ, A. (org.). Temas de educação contemporânea. Paraná: EDUNIOESTE, 2008.

TÓTORA, Silvana. "Ética da vida e o envelhecimento". In: CÔRTE, Beltrina; MERCADANTE, Elisabeth Frohlich; ARCURI, Irene Gaeta. (Org.). Envelhecimento e velhice: um guia para a vida. São Paulo: Vetor, 2006.

VELLAS, Pierre. As oportunidades da Terceira Idade. 1o ed. Paraná: Eduem, 2009.

WORLD Health Organizativo. Envelhecimento ativo: uma política de saúde. Brasília: Organização Pan-Americana da Saúde, 2005. 